\title{
Zastosowanie spektroskopii ramanowskiej do analizy powłok hydroksyapatytowych natryskanych plazmowo
}

\author{
Possibilities of application Raman spectroscopy to analysis \\ of plasma sprayed hydroxyapatite coatings
}

\section{Streszczenie}

W artykule zostały przedstawione wyniki badań powłoki hydroksyapatytowej naniesionej metodą plazmową. Analiza zmian struktury naniesionej powłoki została przeprowadzona metodą spektroskopii ramanowskiej. W celu oszacowania niejednorodności struktury fizykochemicznej wykonano mapowanie wybranego fragmentu powierzchni powłoki pod kątem lokalnych zmian. Do oceny ilościowej występowania hydroksyapatytu w stosunku do innych form fosforanów wapnia wykorzystano parametr $\mathrm{w}$ postaci stosunku intensywności pasma charakterystycznego grupy hydroksylowej $(\mathrm{OH}-)$ do pasma modu pełnosymetrycznego kompleksu $\mathrm{PO}_{4}{ }^{3-}$. Badania wykonano dla dwóch rozdzielczości przestrzennych: niska rozdzielczość - krok $25 \mu \mathrm{m}$, wysoka rozdzielczość - krok $5 \mu \mathrm{m}$. Stwierdzono znaczne wahania wartości zdefiniowanego parametru w obrębie całego badanego fragmentu powłoki, co wskazywało na znaczny i niejednorodny rozkład hydroksyapatytu. Badanie miało na celu ocenę możliwości testowania powłok endoimplantów przy użyciu map ramanowskich.

Słowa kluczowe: hydroksyapatyt; natryskiwanie plazmowe; endoimplanty; spektroskopia ramana

\begin{abstract}
This paper contains results of the study of a hydroxyapatite coating deposited by plasma spraying. Properties variation of a coating was analyzed Raman spectrosocopy method. To assess the heterogeneity of the chemical structure was made the mapping for selected fragment of the surface. To quantify the presence of the hydroxyapatite in relation to other forms of calcium phosphate, ratio of $\mathrm{OH}$ to $\mathrm{PO} 4$ peaks intensities was used. Mapping was made for both of low $(25 \mu \mathrm{m})$ and high $(5 \mu \mathrm{m})$ resolution. There was a significant fluctuations of the structural properties throughout the given fragment of the coating and considerable degradation of hydroxyapatite. The study aimed at evaluating for the possibilities of testing endoimplants coating using Raman mapping.
\end{abstract}

Keywords: hydroxyapatite; plasma spraying; endoimplants; Raman spectrosocopy

\section{Wstęp}

Fosforany wapnia zajmują wyjątkowo ważne miejsce wśród ceramicznych biomateriałów ze względu na wysoką biozgodność. Są one zwykle ortofosforanami, czyli solami trójzasadowego kwasu ortofosforowego $\mathrm{H}_{3} \mathrm{PO}_{4}$. Z punktu widzenia medycyny najistotniejszą odmianą fosforanu jest hydroksyapatyt (HAp), ponieważ jest rzeczywistym, naturalnym budulcem kości, odpowiedzialnym za ich wytrzymałość [1]. W organizmie ludzkim hydroksyapatyt jest stale rozpuszczany i na nowo wydzielany przez komórki kostne, w procesie nazywanym resorpcją [2]. Z tego względu HAp stał się w ostatnich latach ważnym minerałem w zastosowaniach endoprotetycznych $[3 \div 7]$.

Z punktu widzenia struktury krystalicznej, hydroksyapatyt może być nazwany sześcioortofosforanem (V) dwuwodorotlenku dziesięciowapnia, w rezultacie jego wzór sumaryczny przedstawiany jest $w$ formie $\mathrm{Ca}_{10}\left(\mathrm{PO}_{4}\right)_{6}(\mathrm{OH})_{2}$, gdzie stosunek stechiometryczny jonów $\mathrm{Ca} / \mathrm{P}$ wynosi $5: 3$. Należy podkreślić, że jest HAp tylko jednym z wielu reprezentantów szerokiej rodziny materiałów, jakimi są fosforany wapnia. Do innych istotnych z punktu widzenia medycyny przedstawicieli można zaliczyć: amorficzne fosforany wapnia (ACP), dziewięciotlenek difosforanu tetrawapnia (TTCP) oraz fosforan (ortofosforan) wapnia (TCP), których stosunek $\mathrm{Ca} / \mathrm{P}$ mieści się zazwyczaj w granicach $1.5-2$. Wśród nich HAp charakteryzuje się największą rozpuszczalnością w żywym organizmie [1].

Syntetyczny hydroksyapatyt może z powodzeniem pełnić funkcję interfejsu na styku implant -kość. Implanty metaliczne nie zapewniają odpowiedniego związania z tkanką kostną. Pokrycie ich powłoką hydroksyapatytową, która jest resorbowalna, zapewnia doskonałe umocowanie implantu, uniemożliwiające jego przemieszczenie dzięki temu, że tkanki kostne wykazują silne powinowactwo z powłoką, objawiające się jej rozpuszczaniem i przerastaniem naturalnym hydroksyapatytem.

Do nanoszenia powłok stosuje się między innymi metody elektrochemiczne, tam gdzie struktura geometryczna implantu jest skomplikowana. W przypadku prostych geometrii stosuje się zwykle metody natryskiwania plazmowego.

Mgr inż. Szymon Kowalski - Tegeno Sp. z o.o., Kielce; dr inż. Radosław Belka, dr hab. inż. Wojciech Żórawski, prof. PŚw; dr hab. inż. Małgorzata Suchańska, prof. PŚw - Politechnika Świętokrzyska.

Autor korespondencyjny/Corresponding author. belka@tu.kielce.pl 
Daje ona możliwość szybkiego wytworzenia powłoki o grubości od 30 do $500 \mu \mathrm{m}$. Wadą tej metody jest wysoka temperatura procesu oraz gwałtowne chłodzenie, które mogą wywołać amorfizację struktrury hydroksyapatytu, a nawet jego rozkład chemiczny, skutkując zaburzeniem stechiometrii lub powstaniem fazy amorficznej. Temperatura topnienia hydroksyapatytu wynosi $1570{ }^{\circ} \mathrm{C}$, zaś temperatura jego wrzenia to $3227^{\circ} \mathrm{C}[1]$.

Do badania struktury chemicznej i jednorodności powłok hydroksyapatytowych z powodzeniem można wykorzystać metodę spektrometrii ramanowskiej [8]. Metoda ta uznawana za nieinwazyjną technikę identyfikacyjną, bazującą na analizie częstotliwości charakterystycznych drgań złożonych związków chemicznych, w tym kompleksów jonowych. W szczególności, w przypadku hydroksyapatytu obserwowane są 2 intensywne pasma: jedno odpowiadające częstotliwości rezonansowej modu "oddychającego" kompleksu $\mathrm{PO}_{4}{ }^{3-}$, czyli symetrycznych drgań rozciągających wiązań fosfor-tlen $\left(\bmod A_{1}\right)$, przy $v\left(A_{1}\right) \approx 962 \mathrm{~cm}^{-1}$ zaś drugie odpowiadające drganiom rozciągającym grupy hydroksylowej, przy $\mathrm{v}(\mathrm{OH}) \approx 3572 \mathrm{~cm}^{-1}$. Warto podkreślić, iż to drugie drganie nie jest obserwowane w fosforanach pozbawionych grupy $\mathrm{OH}$, a więc wszystkich wymienionych powyżej. Z tego względu stosunek intensywności obu modów może być ilościowym wyznacznikiem zawartości HAp w badanej strukturze.

Standardowy pomiar ramanowski jest punktowy i ogranicza się do analizy obszaru kołowego o średnicy około 3-5 $\mu \mathrm{m}$. Możliwe jest wykonywanie zautomatyzowanego szeregu punktowych pomiarów (tzw. mapowanie ramanowskie), co daje możliwość zbadania przestrzennego rozkładu określonej właściwości. Taki test jest dużo wiarygodniejszy. Pomiary takie wykonane $\mathrm{w}$ regularnych odstępach dają możliwość zbadania zmian własności wewnątrz zadanego obszaru, eliminują błędy wynikające z przypadkowości wyboru punktów pomiarowych oraz dają możliwość wychwycenia charakteru zaburzeń struktury względem wzajemnego położenia punktów pomiaru. Znacząco zwiększa się również szansa wykrycia wtrąceń i zanieczyszczeń.

Celem tego artykułu jest przedstawienie wyników badań powierzchni powłok hydroksyapatytowych, natryskiwanych plasmowo, przy pomocy metody mapowania ramanowskiego. W szczególności analizowano przestrzenny rozkład intensywności modu charakterystycznego grupy $\mathrm{OH}$, stanowiącego miarę zawartości HAp w nanoszonych powłokach.

\section{Metodyka badań}

Powłoka była osadzona na płaskiej próbce ze stali nierdzewnej 1.4510 (OH17T) o wymiarach $15 \mathrm{~mm}$ x $15 \mathrm{~mm}$ x $1 \mathrm{~mm}$. Przed natryskiwaniem plazmą próbka została odtłuszczona i wypiaskowana za pomocą elektrokorundu pod ciśnieniem 0.5 MPa. Zastosowano proszek hydroksyapatytu Sulzer Metco XPT-D-703 (rys. 1). Natryskiwanie plazmą zostało przeprowadzone za pomocą systemu Plancer PN-120 $z$ dozownikiem proszku Thermal Miller 1264. Do naniesienia powłok zostały ustawione następujące parametry: natężenie - $600 \mathrm{~A}$, napięcie - $60 \mathrm{~V}$, ciśnienie gazów - $0.7 \mathrm{MPa}$, odległość dyszy - $100 \mathrm{~mm}$, prędkość podawania proszku - $60 \mathrm{~g} / \mathrm{min}$ [2]. Po osadzeniu grubość powłoki wynosiła około $0.3 \mathrm{~mm}$.

Proszek HAp oraz osadzona na nierdzewnej stali powłoka badane były przy pomocy spektroskopii ramanowskiej. Pomiary przeprowadzono przy pomocy zautomatyzowanego spektrometru micro-Raman Nicolet Almega XR (Thermo Scientific) ze wzbudzeniem $532 \mathrm{~nm}$ (laser Nd:YAG), o mocy ok. $24 \mathrm{~mW}$. Widma były uzyskane w trybie micro mode (zakres $100-4000 \mathrm{~cm}-1,6$ cm-1 rozdzielczość). Uzyskane widma były przetworzone przez oprogramowanie Nicolet Omnic 8 w celu usunięcia tła luminescencyjnego. Wiązkę laserową kierowano prostopadle do powierzchni badanej próbki i ogniskowano przy użyciu wysokoaperturowych, krótkodystansowych obiektywów optycznych, o powiększeniu 10x i 50x). Spektrometr ramanowski jest zintegrowany z mikroskopem optycznym Olympus BX51, umożliwiając również obserwacje mikroskopowe oraz ułatwiające właściwe justowanie i ogniskowanie wiązki. Czas rejestracji każdego widma pomiarowego został ustawiony na 60 sekund. Dzięki możliwości tworzenia map widm pomiary przebiegały w sposób zautomatyzowany. Wykonano dwie mapy. Pierwsza, o niskiej rozdzielczości przestrzennej $(25 \mu \mathrm{m})$, przy użyciu obiektywu o powiększeniu 10x $(N A=0,25)$ obszaru o wymiarach 400 × $275 \mu \mathrm{m}$. Mapa ta składała się z 204 punktów (17 x 12) o rozmiarze plamki lasera ok. $3 \mu \mathrm{m}$. Druga mapa, o wysokiej rozdzielczości $(5 \mu \mathrm{m})$ wykonana została przy użyciu obiektywu o powiększeniu 50x (NA = 0,5). Obszar o rozmiarze $60 \times 65 \mu \mathrm{m}$ było mapowane przez 182 punkty (13 x 14), przy czym rozmiar plamki lasera wynosił ok. $1 \mu \mathrm{m}$. Wykonano również porównawcze badanie samego proszku przed nanoszeniem przy parametrach identycznych jak przy badaniu w wysokiej rozdzielczości. Badanie to zostało powtórzone 3-krotnie.

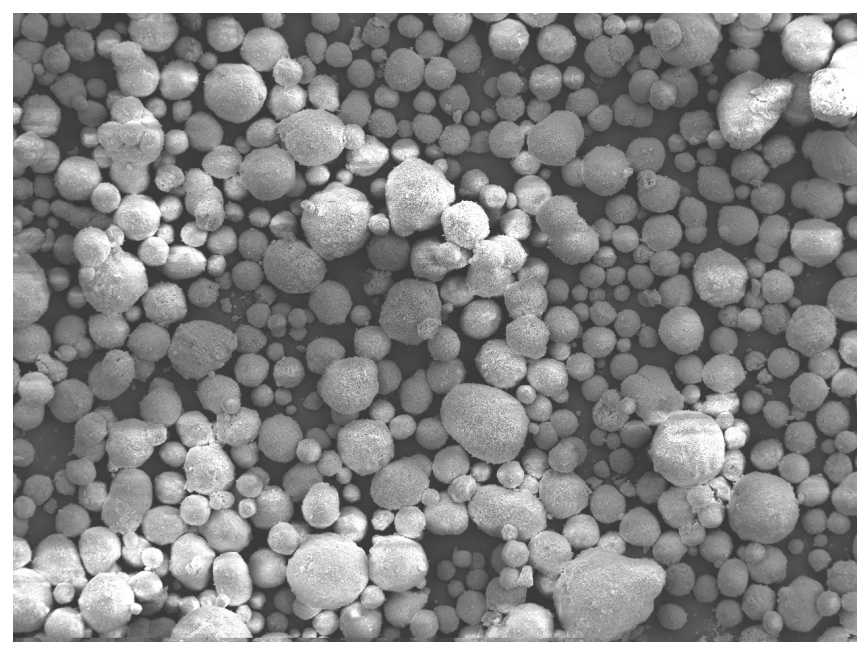

Rys. 1. Proszek hydroksyapatytowy Sulzer Metco XPT-D-703

Fig. 1. Sulzer Metco XPT-D-703 Hydroxyapatite powder

\section{Wyniki badań i dyskusja}

Na rysunku 2 porównano punktowe widma ramanowskie proszku i powłoki HAp, z zaznaczonymi dwoma podstawowymi pasmami charakterystycznymi. Pomiary wykazały silny zanik piku $\mathrm{OH}$ w materiale po naniesieniu powłoki metodą plazmową. Stosunek $\mathrm{I}(\mathrm{OH}) / \mathrm{II}(\mathrm{PO} 4)$ dla proszku przed nanoszeniem oszacowano na ok. 0,42-0,43 i w dalszych badaniach traktowany był jako miarodajny parametr reprezentujący obecność hydroksyapatytu.

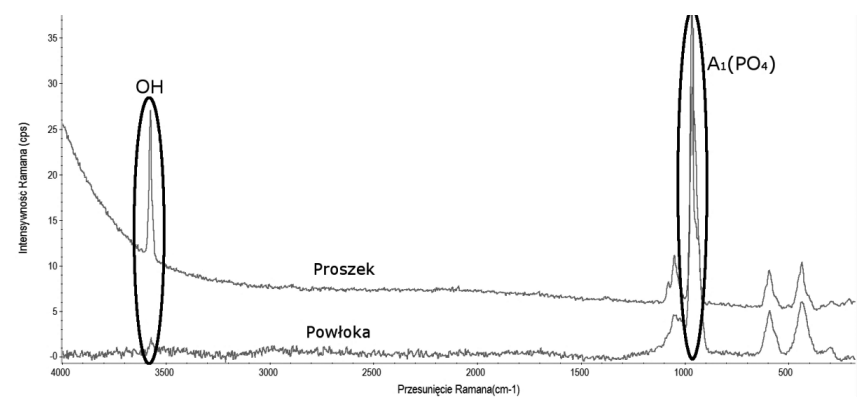

Rys. 2. Punktowe widma Ramana dla proszku i powłoki

Fig. 2. Spot Raman spectra for raman powder and coating 
Na rysunku 3 przedstawiono obraz mikroskopowy wybranego fragmentu powierzchni powłoki (obiektyw 10x) wraz z naniesioną siatką punktów pomiarowych (krok $25 \mu \mathrm{m}$ ). Obraz z mikroskopu świetlnego powłoki HAp wskazuje na wyraźną chropowatość próbki, co negatywnie wpływa przeprowadzenie mapowania ramanowskiego. Dlatego też użycie parametru w postaci stosunku intensywności dwóch wybranych pasm pozwoliło uzgodnić wyniki pomiarów.

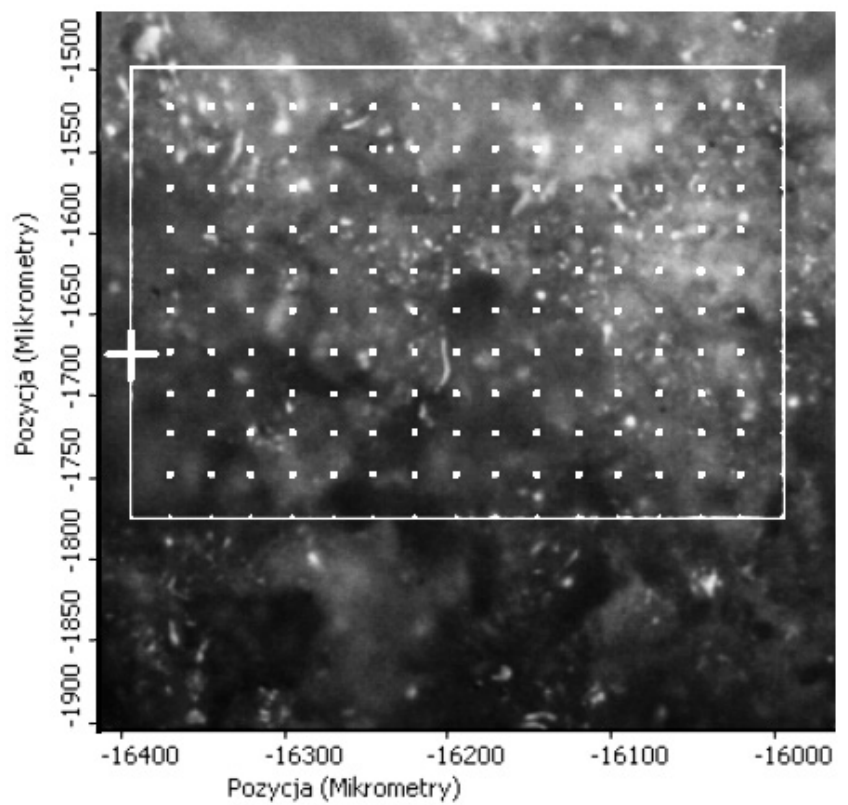

Rys. 3. Próbkowanie mapy widm ramanowskich niskiej rozdzielczości $(25 \mu \mathrm{m})$

Fig. 3. Sampling maps of Raman spectrum in low resolution (25 microns)

Rysunek 4 przedstawia odpowiadającą rysunkowi 3 mapę rozkładu stosunku intensywności I(OH)/I(PO4). Obszary jaśniejsze oznaczają miejsca o większej zawartości hydroksyapatytu. Wyniki wskazują na znaczny spadek intensywności pasma modu $\mathrm{OH}$ w powłoce naniesionej plazmowo w stosunku do proszku. Stosunek I(OH)/I(PO4) wynosił średnio około 0,05-0,06, czyli był blisko 8-krotnie mniejszy niż w przypadku proszku. Oznaczać to może, że średnio ponad 85\% HAp rozpadło się i przekształciło $w$ inne odmiany fosforanów. Analiza danych literaturowych wskazuje, że możliwymi i bardzo prawdopodobnymi produktami rozpadu są TCP i TTCP w stosunku 2:1 [7,9]. Należy zauważyć, że rozpad HAp nie jest jednakowo intensywny w badanym obszarze. Występują obszary o stosunku pików przewyższającym wartość 0,3 (co odpowiada zawartości HAp na poziomie 70\% i więcej), jak również miejsca o całkowitym zaniku piku $\mathrm{OH}$.

$\mathrm{Na}$ rysunkach 5 i 6 przedstawiono analogiczne rezultaty uzyskane w trybie większej rozdzielczości (krok $5 \mu \mathrm{m}$ ). Również w tym przypadku obraz mikroskopowy nie daje możliwości

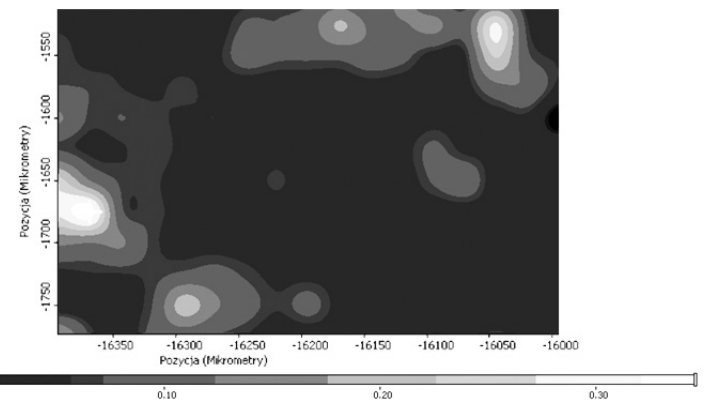

Rys. 4. Mapa niskiej rozdzielczości $(25 \mu \mathrm{m})$ stosunku I(OH)/II(PO4) Fig. 4. Low resolution map $(25 \mu \mathrm{m})$. The ratio of $\mathrm{I}(\mathrm{OH}) / \mathrm{II}(\mathrm{PO} 4)$ chociażby wstępnej analizy struktury chemicznej. Mapa rozkładu intensywności I(OH)/I(PO4) wykazała jednak zdecydowanie większą jednorodność powłoki, ponieważ zaobserwowany zakres wartości stosunku I(OH)/I(PO4) uległ zawężeniu do $0-0,08$. Pomiar ten wykazał istnienie dużo większej liczby punktów całkowitego zaniku pasma modu $\mathrm{OH}$.

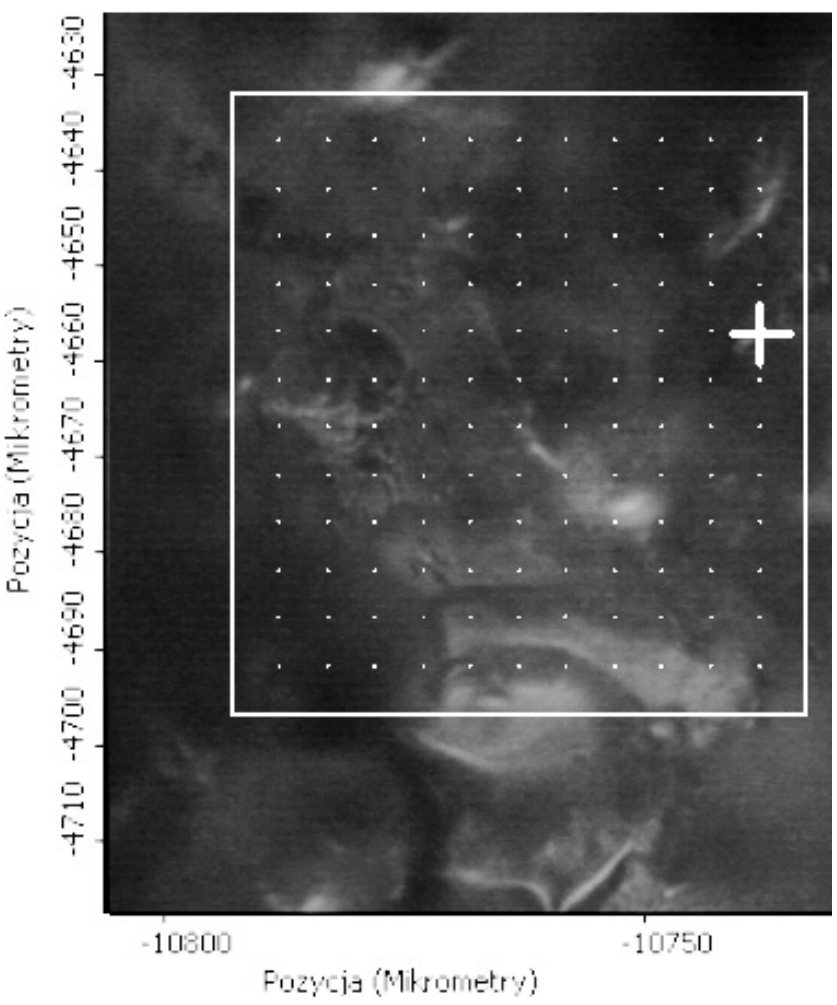

Rys. 5. Próbkowanie mapy widm ramanowskich wysokiej rozdzielczości $(5 \mu \mathrm{m})$

Fig. 5. Sampling maps of Raman spectrum in high resolution (5 microns)

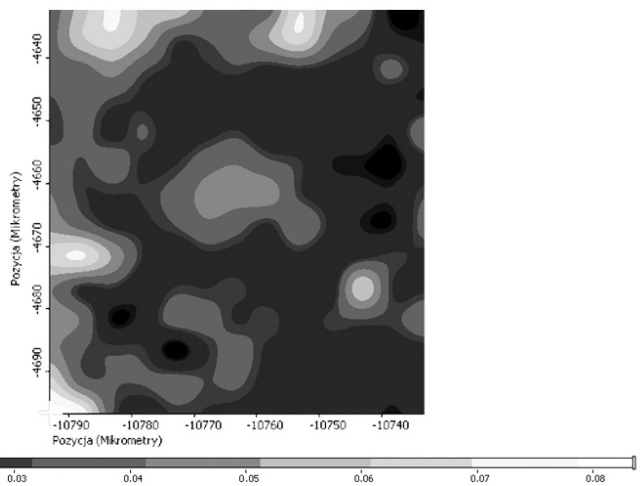

Rys. 6. Mapa wysokiej rozdzielczości $(5 \mu \mathrm{m})$ stosunku I(OH)/II(PO4) Fig. 6. High resolution map $(5 \mu \mathrm{m})$. The ratio of $\mathrm{I}(\mathrm{OH}) / \mathrm{II}(\mathrm{PO} 4)$

$\mathrm{Na}$ podstawie przeprowadzonych można stwierdzić, że poza nielicznymi miejscami, gdzie zawartość hydroksyapatytu w powłoce jest dominująca (ponad 60- 70\%), w przeważającej większości obszaru obserwuje się prawie całkowity rozkład HAp, tj od 80 do $100 \%$ tego związku ulega rozkładowi w procesie natryskiwania plazmowego. Rozpad hydroksyapatytu skutkuje również zaburzeniem stechiometrii jonów wapnia i fosforu, co potwierdzają również badania mikroanalizy rentgenowskiej prezentowane w [10]. Przeprowadzona analiza dotyczy jedynie warstwy przypowierzchniowej, która jest poddawana laserowemu wzbudzeniu i nie obejmuje całości mikrostruktury powłoki. 


\section{Wnioski}

Analiza przestrzennego rozkładu intensywności pasm charakterystycznych wskazuje przede wszystkim na fakt znacznego, choć wyraźnie niejednorodnego rozpadu hydroksyapatyytu w procesie nanoszenia powłoki przy zastosowaniu procesu natryskiwania plazmowego. Otrzymane wyniki wskazują, że ok. $85-90 \%$ natryskiwanego hydroksyapatytu ulega przetransformowaniu w inne odmiany fosforanów (prawdopodobnie w fosforan trójwapniowy i fosforan tetrawapnia). Ponadto, średnio co kilkaset $\mu \mathrm{m}$ obserwuje się obszary, w których HAp nie uległ zdecydowanej przemianie. Rozpad hydroksyapatytu skutkuje zaburzeniem stechiometrii jonów wapnia i fosforu, co potwierdzają badania mikroanalizy rentgenowskiej prezentowane w [10]. Należy przy tym podkreślić, że średni stosunek $\mathrm{Ca} / \mathrm{P}$ powinien zostać zachowany i być zbliżony do wartości typowych dla HAp, co jest istotne z medycznego punktu widzenia.

Badania były współfinansowane przez Europejski Fundusz Rozwoju Regionalnego w ramach Programu Operacyjnego Innowacyjna Gospodarka 2007-2013 (Nr UDA-POIG.01.03.01-14-071/08-10).

Pomiary ramanowskie przeprowadzono przy użyciu sprzętu współfinansowanego przez Europejski Fundusz Rozwoju Regionalnego w ramach Programu Operacyjnego Innowacyjna Gospodarka na lata 2007-2013 (Nr POIG 02.02.00-26-023/08-00).

\section{Literatura}

[1] Sobczak A., Kowalski Z., "Materiały hydroksyapatytowe stosowane w implantologii" (http://suw.biblos.pk.edu.pl/resources/i6/i1/i4/r614/ SobczakA_MaterialyHydroksypatytowe.pdf).

[2] Elliott, J.C., [Structure and Chemistry of the Apatite and Other Calcium Orthophosphates], Elsevier, Amsterdam, (1994).

[3] Huracek, J. and Spirig, R., "The effect of hydroxyapatite coating on the fixation of hip prostheses," Arch Orthop Trauma Surg 113, $72-77$ (1994).

[4] Dumbleton, J. and Manley, M.T., "Hydroxyapatite-coated prostheses in total hip and knee arthroplasty," J Bone Joint Surg Am. 86-A(11), 2526-40 (2004).

[5] Liao, S.L., Kao, S.C.S., Tseng, J.H.S. and L-K Lin, L., "Surgical coverage of exposed hydroxyapatite implant with retroauricular myoperiosteal graft," Br J Ophthalmol. 89 (1), 92-95 ( 2005)

[6] Herrera, A., Mateo, J., Gil-Albarova, J., Lobo-Escolar, A., Ibarz, E., Gabarre, S., Más, Y. and Gracia, L., "Cementless Hydroxyapatite Coated Hip Prostheses, BioMed Research International," BioMed Research International 2015, 13 (2015).
[7] J. L. Ong and D. C. N. Chan, "Hydroxyapatite and Their Use As Coatings in Dental Implants: A Review," Critical Reviews ${ }^{T M}$ in Biomedical Engineering, 28(5\&6):1-41 (1999).

[8] Koutsopoulos, S. "Synthesis and characterization of hydroxyapatite crystals: A review study on the analytical methods", J Biomed Mater Res. 2002 62(4):600.

[9] C. Moseke, U. Gbureck, Tetracalcium phosphate: Synthesis, properties and biomedical applications, Acta Biomaterialia 6 (2010) 3815-3823

[10] R. Belka, S. Kowalski, W. Żórawski, M. Suchańska, "A study of plasma sprayed HAp coatings using the EDX and Raman methods", TRANSCOM 2015 Conference, 22-24 June 2015, Żylina, Slovakia.

[11] N. Curry, K. VanEvery , T.Snyder, N. Markocsan, "Thermal Conductivity Analysis and Lifetime Testing of Suspension Plasma-Sprayed Thermal Barrier Coatings", Coatings 2014, 4(3). 